\title{
MUDANÇAS RECENTES NOS PROCESSOS DE GOVERNANÇA TERRITORIAL EM PORTUGAL
}

\author{
SUSANA MONTEIRO ${ }^{1}$
}

\begin{abstract}
Resumo - Os Estados-nação actuam hoje num contexto social manifestamente diverso daquele em que nasceram e se consolidaram, o que os tem "forçado" a reequacionar o seu modus operandi e o seu papel na sociedade e na economia.

É neste novo cenário de forte fragmentação e complexidade social que surge a actual Política de Cidades Polis XXI e ganha relevo e pertinência o estudo de novos modelos de governança urbana e desenvolvimento territorial.

Na presente nota procura-se: 1) sistematizar um conjunto de considerações conceptuais sobre os desafios contemporâneos à governança territorial que afectam os Estados-nação ocidentais, em geral, e Portugal, em particular; 2) enquadrar a Política de Cidades Polis XXI neste novo cenário; 3) propor uma matriz de avaliação do desempenho das parcerias inter-organizacionais enquadradas pela Política de Cidades Polis XXI, enquanto novo mecanismo de governança territorial.
\end{abstract}

Palavras-chave: Política de Cidades Polis XXI, governança urbana, colaboração inter-organizacional e metodologias de avaliação de performance.

Abstract - Recent Changes in terRitorial governance Processes IN PortuGAL. The current context in which nation-states find themselves is clearly different from that in which they were founded and consolidated. This fact has given rise to the need to rethink both their modus operandi and their role in society and the economy.

Against this new, fragmented and complex social setting, the Urban Policy Polis XXI has evolved and become increasingly relevant and useful for the study of new models of urban governance and territorial development.

This note seeks to: 1) sum up a set of conceptual considerations with regard to the challenges in terms of territorial governance that are faced by Western nationstates in general and Portugal in particular; 2) discuss the Urban Policy Polis XXI against this new and evolving background; and 3) propose a framework for evaluating the performance of the inter-organizational partnerships promoted within the context of the Urban Policy Polis XXI as a new territorial governance mechanism.

Recebido: 31/10/2008. Revisto: 19/12/2008. Aceite: 29/12/2008.

1 Técnica superior no Observatório do QREN. E-mail: susana.monteiro@observatorio.pt 
Key words: Urban Policy Polis XXI, urban governance, inter-organizational collaboration and performance evaluation methodologies.

Résumé - CHANGEMENTS RÉCENTS DANS LES PROCESSUS DE GOUVERNANCE TERRITORIALE AU PORTUGAL. Les États-nations agissent aujourd'hui dans un contexte bien différent de celui dans lequel ils sont nés et se sont développés. La politique urbaine portugaise, dite Polis XXI, doit agir dans ce nouveau contexte de difficile coordination entre les acteurs et de faible culture civique. D'où l'intérêt de l'étude de nouveaux modèles de gouvernance urbaine et de développement territorial. On recherche ici: 1) à systématiser quelques concepts relatifs aux défis auxquels doit faire face la gouvernance territoriale des États-nations occidentaux et du Portugal en particulier; 2) à situer la Polis XXI dans ce nouveau contexte; 3) à proposer un système d'évaluation des réalisations des associations d'organismes, encadrés par la Polis XXI, en tant que nouveau mécanisme de gouvernance territoriale.

Mots-clés: Politique Urbaine Polis XXI, gouvernance urbaine, collaboration entre organismes et méthodologie pour l'évaluation des réalisations.

\section{DESAFIOS CONTEMPORÂNEOS À GOVERNANÇA TERRITORIAL}

As sociedades ocidentais têm vindo a ser confrontadas com um conjunto emergente de fenómenos sociais, políticos e económicos. Refiram-se a título de exemplo: 1) a crise financeira do Estado, fruto do desaceleramento e instabilidade do crescimento económico e consequente redução de receitas e do aumento de gastos públicos estruturais; 2) o novo quadro demográfico, caracterizado por uma forte pressão migratória, pelo envelhecimento da população e pela não renovação das gerações; 3) as novas janelas de oportunidades trazidas pelas Tecnologias de Informação e Comunicação; 4) a crescente complexidade das dinâmicas territoriais, cuja análise e intervenção exigem um quadro de maior interactividade entre as diversas disciplinas de conhecimento; 5) a crise do modelo de democracia representativa.

Estes fenómenos, operando em conjunto, concorrem para uma new ecology (Savitch, 1998) marcada por uma profunda fragmentação, complexificação e especialização sócio-económica, que coloca desafios importantes quer ao Estado, que se viu forçado a repensar o seu papel na sociedade, quer à própria sociedade que se viu impelida a auto-organizar-se de modo a dar resposta a problemas e necessidades cuja solução era assegurada, outrora, pelo Estado e seus organismos.

Esta new ecology tem implicações directas nos processos de desenvolvimento urbano, que deixam de estar apenas associados ao desempenho económico-financeiro de uma dada comunidade, mas também à sua capacidade em manter elevados níveis de eficiência sem colocar em causa os sistemas ambiental e social.

A gestão deste triângulo do desenvolvimento urbano (eficiência económica, sustentabilidade ambiental e coesão social) encerra em si desafios concretos ao sistema político urbano e às democracias representativas que o suportam, colocando a tónica na necessidade de repensar os modelos de governança urbana, entendida “... não só como o mero governo da cidade, mas como um sistema de relações entre instituições, organizações e indivíduos, que assegura as escolhas colectivas e a sua concretização" (Ascher, 1998). 
Todavia, estas mudanças de enfoque não exigem necessariamente que se criem novas estruturas governativas. Exigem, acima de tudo, que se repensem as relações entre as já existentes, mediante princípios de determinação, pragmatismo e inovação - the three main ingredients of this new urban governance (Cavallier, 1998).

\section{A POLÍTICA DE CIDADES POLIS XXI}

O XVII Governo Constitucional Português reconhecendo, por um lado, a inevitabilidade desta new ecology e dos reptos que a mesma coloca aos processos de desenvolvimento urbano, e tendo presente, por outro lado, as fragilidades do Sistema Urbano Nacional, assumiu, como grande desígnio nesta matéria, a produção de um referencial político que enquadrasse estrategicamente a temática urbana.

Para o efeito, gizou uma Política de Cidades Polis XXI que chama a si um conjunto de instrumentos ${ }^{2}$ e fontes de financiamento complementares que procura contribuir para a resolução de muitos dos problemas para o ordenamento do território em Portugal, identificados no Programa Nacional de Política de Ordenamento do Território (PNPOT). Dos 24 problemas aí recenseados saliento um que considero ser transversal e condicionador da mitigação de todos os outros: a "dificuldade de coordenação entre os principais actores institucionais, públicos e privados, responsáveis por políticas e intervenções com impacte territorial" (MAOTDR, 2007: 127). Se a esta dificuldade adicionarmos a "ausência de uma cultura cívica valorizadora do ordenamento do território [e o] incipiente desenvolvimento da cooperação territorial supra-municipal na programação e gestão de infra-estruturas e equipamentos colectivos" (MAOTDR, 2007: 127), deparamo-nos com um quadro de governação territorial manifestamente limitado e limitador, face às novas exigências do desenvolvimento territorial.

A Política de Cidades Polis XXI procura, de forma explícita, contribuir para a superação desta dificuldade, propondo instrumentos de política suportados por uma abordagem descentralizada que estimula a iniciativa local (lato sensus) e promove a emergência de modelos inovadores de articulação entre actores urbanos. Tal objectivo é abordado através do "... estimular (de) novas formas de "governação", baseadas numa maior participação dos cidadãos, num envolvimento mais empenhado dos diversos actores urbanos - públicos, privados e associativos - e em mecanismos flexíveis de cooperação entre cidades e entre estas e os espaços envolventes." (MAOTDR, s.d.: 7) Esta é, na minha opinião, a grande inovação da Política de Cidades Polis XXI.

A Política de Cidades Polis XXI define como principais instrumentos nesta área dois modelos de colaboração (MAOTDR, s.d.):

Parcerias para a Regeneração Urbana - Correspondem a programas de acção comuns para a regeneração de áreas intra-urbanas específicas (centros históricos, frentes ribeirinhas, etc.), tendo como suporte uma estrutura formal de parceria local que pode incluir os mais diversos actores urbanos públicos e privados (Municípios, empresas,

2 A Política de Cidades Polis XXI materializa-se em quatro instrumentos, a saber: Parcerias para a Regeneração Urbana, Redes Urbanas para a Competitividade e Inovação, Acções Inovadoras para o Desenvolvimento Urbano e Equipamentos Estruturantes do Sistema Urbano Nacional. 
associações empresariais, serviços da administração central, concessionários de serviços públicos, instituições de ensino, moradores e suas associações, etc.);

Redes Urbanas para a Competitividade e Inovação - Correspondem a redes de actores urbanos envolvidos num processo de cooperação estratégica (Municípios, empresas, associações empresariais, instituições de ensino superior, centros de I\&D, agências e associações de desenvolvimento local e regional, serviços da administração central, ONG, etc.) para o reforço dos factores de competitividade, do potencial económico e da projecção internacional de uma cidade ou de redes de cidades organizadas, quer numa relação de proximidade quer numa base temática.

Em ambos os instrumentos é atribuída significativa importância à cooperação institucional entre os agentes de desenvolvimento dos territórios. Dizendo de outra forma, estes instrumentos assentam na capacidade de integrar territorialmente políticas, medidas e acções dispersas e avulsas e na aptidão de promover acções concertadas e coerentes de desenvolvimento territorial. Este desafio traduz o reconhecimento de uma paisagem organizacional densificada, onde a capacidade institucional, pública e privada, se fragmentou e especializou, e onde nenhum agente de desenvolvimento detém toda a informação e potencial de acção necessários para fazer face a problemas de crescente complexidade e dinamismo. Por conseguinte, faz todo o sentido sensibilizar e estimular os diferentes actores endógenos dos territórios a desenvolverem interacções mais amplas, sistémicas e duradouras.

\section{DESEMPENHO DAS PARCERIAS INTER-ORGANIZACIONAIS: COMO AVALIAR A COLABORAÇÃO ENTRE AGENTES?}

Tanto as Parcerias para a Regeneração Urbana como as Redes Urbanas para a Competitividade e Inovação já entraram em fase de execução, tendo chegado o momento de planear os seus sistemas de monitorização e avaliação.

Considerando o assinalável potencial de inovação destes instrumentos, designadamente ao nível dos mecanismos de colaboração inter-organizacional que promovem, parece relevante reflectir sobre os principais critérios e dimensões que poderão esboçar um futuro referencial de avaliação destes instrumentos naquele domínio e, por conseguinte, de avaliação dos resultados da Política de Cidades Polis XXI em matéria de estímulo a novas formas de governança urbana.

A proposta que se apresenta resulta de uma reflexão sobre redes e parcerias interorganizacionais sectoriais de base territorial em geral, e não da análise concreta dos instrumentos de política em questão, até porque o mesmo não seria ainda cronologicamente possível. Por conseguinte, as propostas agora apresentadas devem ser entendidas como pistas de reflexão para um futuro modelo de avaliação e apenas enquanto tal.

Wilson-Grau e Nuñez (2007) propõem uma matriz de avaliação do desempenho das parcerias inter-organizacionais passível de ser adaptada à temática da cooperação inter-organizacional no âmbito da Política de Cidades Polis XXI. O contributo destes autores assenta num modelo que combina quatro critérios de avaliação com três dimensões operacionais relativas ao funcionamento de uma parceria inter-organizacional. Os referidos critérios e dimensões são descritos nos parágrafos seguintes. 
1. O primeiro critério, que os autores consideram fundamental integrar no modelo de avaliação, diz respeito aos níveis de democracia registados, quer no planeamento quer na operacionalização do trabalho da parceria. Com este critério é possível aferir as condições de equidade nas relações e no exercício do poder no seio da parceria, assim como os níveis de conhecimento e concordância face aos valores, objectivos, estratégias e modos de utilização dos recursos da estrutura.

A análise deste critério poderá incidir na resposta a questões de avaliação, tais como: O processo de tomada de decisão é considerado pelos parceiros como justo e inclusivo (nível de participação na tomada de decisão)? Existe um sentimento de pertença à parceria por parte dos seus membros (nível de identificação com os valores e outros requisitos)? Os membros partilham e têm acesso equitativo aos recursos da parceria (nível de partilha e acesso aos recursos)? A estrutura é tendencialmente horizontal (nível de hierarquização da estrutura)?

2. O segundo critério, a incluir na matriz de avaliação, reside na diversidade $e$ complementaridade entre os actores urbanos envolvidos na parceria. Com este critério é possível, em primeira instância, compreender o nível de fragmentação e especialização da paisagem organizacional do território, bem como a sua representatividade na parceria, em função dos temas abrangidos e dos problemas a suprir. É, ainda, possível apreender os níveis de atractividade da própria parceria e de inclusividade organizacional da mesma.

As questões de avaliação que dão corpo a este critério serão as seguintes: Estão representadas na parceria todas as entidades cuja missão e localização territoriais seriam pertinentes na prossecução dos objectivos (nível de inclusividade)? As áreas de actividade e missões dos parceiros são complementares entre si, de forma a permitir atingir os objectivos da parceria (nível de complementaridade)? Existe diversidade quanto às competências e recursos organizacionais dos parceiros, de forma a ser possível cumprir os objectivos e executar as actividades (nível de diversidade)?

3. O terceiro critério, que deverá ser integrado no modelo, assenta nos níveis de dinamismo de cada parceiro e da própria parceria, como um todo. Com este critério é possível compreender em que medida a estrutura é activa e eficaz. Este é um factor preponderante para o cumprimento dos objectivos da parceria, bem como para a manutenção de elevados índices de motivação e satisfação de cada parceiro. É com base nos resultados conseguidos e na mudança efectivamente induzida que a parceria consegue, não raras vezes, manter-se coesa e actuante.

As três questões que se seguem ilustram a forma como a análise do critério poderá ser concretizada: Os membros têm iniciativa e influenciam o desenvolvimento da parceria (nível de iniciativa e de incorporação do mesmo)? O efeito da parceria é maior do que a soma das actividades individuais dos seus membros (valor acrescentado da parceria)? A parceria aprende com a experiência? É uma learning organization (nível de aprendizagem colectiva)?

4. O último critério, que a matriz de avaliação do desempenho das parcerias deverá contemplar, reside na eficácia e excelência do trabalho desenvolvido pelos parceiros e, por conseguinte, da parceria. A qualidade da intervenção é, inequivocamente, resultante da excelência dos membros da parceria. Com este critério é possível avaliar as competências organizacionais e os capitais humano, social e relacional de cada parceiro e a 
forma como contribuem para a excelência do todo. É ainda possível assimilar o nível de interacção que a parceria mantém com a sua envolvente, assim como o grau de coerência (interna e externa) do trabalho que desenvolve.

A análise deste critério poderá incidir na resposta a questões de avaliação, tais como: As estratégias e linhas de acção da parceria são coerentes com as mudanças territoriais que pretende induzir (nivel de coerência)? As qualificações do pessoal da parceria estão adequadas às suas responsabilidades (nível de qualificação do capital humano)? A parceria é capaz de envolver outros actores sociais (capital social)? O trabalho é planeado, monitorizado e avaliado (planeamento e avaliação)?

A análise destes quatro critérios de avaliação do desempenho da parceria deverá contemplar o cruzamento com três dimensões operacionais: 1) uma dimensão de cariz mais estratégico, relacionada com os objectivos e estratégias de intervenção da própria parceria; 2) uma outra de índole mais operacional, referente à organização e gestão da estrutura; 3) e uma última, de natureza relacional, respeitante à liderança e participação na parceria.

O Quadro I sintetiza esta proposta de matriz de avaliação das parcerias em geral, e das parcerias da Política de Cidades Polis XXI em particular, apresentando uma proposta mais alargada de questões de avaliação.

Todas as dimensões e critérios referidos devem ser avaliados segundo uma perspectiva contextual, na medida em que a new ecology mencionada no primeiro ponto deste texto, afecta, de modo diferenciado, os territórios e as suas paisagens organizacionais. Tal situação acontece na medida em que os "filtros", ou seja, os sistemas socioculturais e valorativos de cada território determinam a forma como os efeitos se fazem sentir e como as organizações lhes dão resposta.

Por conseguinte, a avaliação do desempenho das parcerias inter-organizacionais de base territorial deverá ter em consideração um conjunto de factores contextuais que balizam a actuação destas estruturas e que, por essa circunstância, condicionam os resultados da avaliação. Não se pretende apresentar uma lista exaustiva desses factores contextuais; no entanto, existem alguns que são claros e que é útil recensear, enquanto ponto de partida para um aprofundamento da reflexão em torno do modelo de avaliação das parcerias inter-organizacionais no âmbito da Política de Cidades Polis XXI.

Factor contextual 1 - Qualificação do capital institucional e político dos territórios - O bom desempenho de uma parceria depende da qualidade, em termos de dinamismo e de poder de iniciativa, da paisagem organizacional pública e privada dos territórios. Ou seja, é difícil pensar em novos modelos de governança urbana, nomeadamente os mais colaborativos, quando o número de instituições presentes no território é reduzido e a sua capacidade de acção é frágil. Construir e fortalecer a capacidade institucional dos territórios é um factor crítico para o sucesso das parcerias. Um outro factor prende-se com o capital político dos territórios, ou seja, com as lideranças das entidades públicas, que se pretendem cada vez mais democráticas, transparentes, descentralizadoras e capazes de estabelecer visões de futuro para as suas próprias organizações e para os territórios que gerem.

Factor contextual 2 - Grau de ampliação da iniciativa local - No estabelecimento daquelas visões de futuro é premente o reconhecimento, por parte da administração local, 


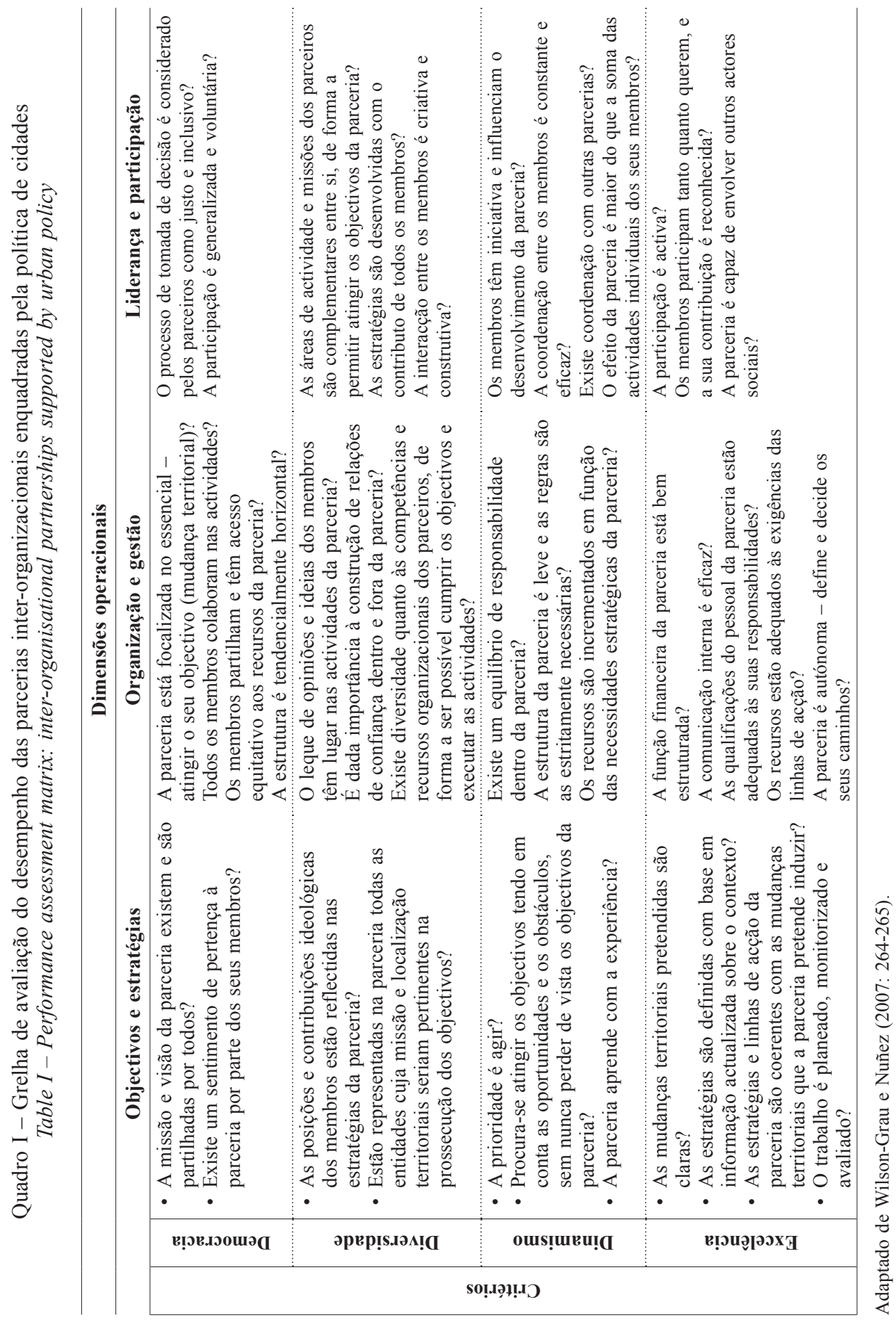


da importância central de outros actores urbanos nos processos de governança e de desenvolvimento territorial. $\mathrm{O}$ sucesso de uma parceria depende, também, de uma diferente divisão do trabalho entre sector público e privado, e do reconhecimento da importância deste último no garante de elevados níveis de satisfação por parte dos munícipes face aos serviços municipais. Depende, ainda, da forma como se assume, afirma e aplica, também ao nível local, o conceito de subsidiariedade, permitindo que as organizações presentes no território, com missões e vocações específicas, clarifiquem o seu lugar e o seu papel na definição, implementação e avaliação das políticas públicas locais.

Factor contextual 3 - Democratização do tecido organizacional dos territórios - A ampliação da iniciativa local depende, como foi referido no ponto anterior, do entendimento que os governos locais têm da forma como podem colaborar com os demais agentes de desenvolvimento, mas depende, igualmente, do entendimento que estes últimos têm desses processos colaborativos e dos níveis de autonomia de cada agente nessa colaboração. A existência de uma sociedade civil e de um tecido empresarial local, efectivamente livres e autónomos, com poder e independência na argumentação e intervenção, constituem factores incontornáveis para o bom desempenho de uma parceria.

Factor contextual 4 - Autonomia/independência institucional - Se a independência política das organizações é vital para a existência de uma parceria efectiva, também o é a independência financeira. O Estado tem estimulado a criação de uma série de entidades não públicas de base local, por via do apoio subsidiário, que asseguram a prestação de muitos serviços públicos. Também o poder local tem estimulado o surgimento de entidades não públicas por via da atribuição de subsídios. Em qualquer dos casos verifica-se uma dependência excessiva, em matéria de recursos financeiros, a qual limita a participação destas organizações nos processos colectivos de tomada de decisão. Também em Portugal a lei do mecenato tem pouca expressão e as organizações não públicas apresentam pouca criatividade na busca de novas fontes de financiamento, registando-se ainda um forte sentimento de paternalismo em relação ao Estado e ao poder local. Se a este propósito podemos dar como exemplo as colectividades desportivas e culturais, ou as instituições de solidariedade social, há que não esquecer que muito do tecido económico do país depende de apoios financeiros públicos ou da aquisição de bens e serviços por parte dos organismos públicos; são eles, em muitos casos, os seus principais clientes, o que também aqui não permite uma independência e autonomia financeiras totais.

Factor contextual 5 - Qualificação do capital humano e das lideranças - Um último factor contextual que importa ter em conta quando se procura analisar o desempenho de parcerias reside na forma como se garante um trabalho de maior qualidade e uma participação na tomada de decisão suportada por instrumentos de maior reflexão técnica. Se existem organizações não públicas, como as entidades de investigação e ensino, cuja qualificação do capital humano é indiscutível, existem outras cujo quadro de pessoal é manifestamente deficitário nesta matéria. Se a esta circunstância acrescentarmos o facto de o défice de liderança ser ainda uma realidade em diversas organizações, fruto do próprio enquadramento legal das associações em Portugal, deparamo-nos com um cenário contextual muito complexo, que importa considerar na avaliação do desempenho das parcerias inter-organizacionais. 
Sintetizando: há manifesta actualidade e relevância nos novos modelos de colaboração inter-organizacional que a Política de Cidades Polis XXI pretende estimular junto dos agentes responsáveis pela governança dos territórios. Trata-se, de facto, de um entendimento bastante lúcido dos desafios que se colocam aos processos de desenvolvimento territorial em Portugal.

Pese embora a concordância generalizada em torno da necessidade daqueles modelos de colaboração, importa destacar a importância da avaliação de desempenho das estruturas que os materializam - as parcerias inter-organizacionais -, enquanto etapa imprescindível do ciclo da operacionalização da Política de Cidades Polis XXI.

Neste sentido, há que ter em conta que o bom desempenho de uma parceria interorganizacional não é líquido, requerendo um esforço avaliativo que acautele o conhecimento concreto das causas e consequências do seu sucesso ou insucesso, e que, por essa via, contribua para uma aprendizagem colectiva e consequente melhoria dos instrumentos de promoção do desenvolvimento territorial em Portugal.

Aquele conhecimento só é relevante e útil se enquadrado num novo entendimento da avaliação de políticas públicas, que enfatize os contextos territorial, temporal e relacional em que se desenvolvem, e que não se cinja a análises meramente quantitativas e financeiras, que se esgotam no horizonte temporal de operacionalização dos instrumentos de política.

É neste sentido que uma avaliação sistematizada da componente colaborativa da Política de Cidades Polis XXI, pode constituir, efectivamente, um marco nos processos de avaliação de políticas públicas em Portugal.

\section{AGRADECIMENTOS}

Agradeço as leituras e sugestões dos referees da revista Finisterra - Revista Portuguesa de Geografia que tiveram um papel imprescindível na reformulação do texto original.

\section{BIBLIOGRAFIA}

Ascher F (1998) Metapolis. Acerca do futuro da cidade. Celta Editora, Lisboa.

Cavallier G (1998) Challenges for urban governance in the european union. European Foundation for the Improvement of Living and Working Conditions, Dublin.

Ministério do Ambiente, do Ordenamento do Território e do Desenvolvimento Regional (MAOTDR) (2007) PNPOT - Programa Nacional da Política de Ordenamento do Território. MAOTDR, Lisboa.

Ministério do Ambiente, do Ordenamento do Território e do Desenvolvimento Regional (MAOTDR) (s.d.) Politica de Cidades Polis XXI. MAOTDR, Lisboa.

Savitch H V (1998) The ecology of public-private partnerships: Europe. In Pierre J (ed.) Partnerships in urban governance. European and American Experiences. MacMillan, London.

Wilson-Grau R, Nuñez M (2007) Evaluating international social change networks. Development in Practice, 17(2): 258-271. 